\title{
FOREST FIRE PREDICTION IN NORTHERN SUMATERA USING SUPPORT VECTOR MACHINE BASED ON THE FIRE WEATHER INDEX
}

\author{
Darwis Robinson Manalu ${ }^{1,2}$, Muhammad Zarlis ${ }^{1}$, \\ Herman Mawengkang ${ }^{1}$ and Opim Salim Sitompul ${ }^{1}$ \\ ${ }^{1}$ Program Studi Doktor (S3) Ilmu Komputer, Fakultas Ilmu Komputer dan \\ Teknologi Informasi, Universitas Sumatera Utara, Medan, \\ North Sumatera-20222, Indonesia \\ ${ }^{2}$ Universitas Methodist Indonesia, Medan, Sumatera Utara, Indonesia
}

\begin{abstract}
Forest fires are a major environmental issue, creating economical and ecological damage while dangering human lives. The investigation and survey for forest fire had been done in Aek Godang, Northern Sumatera, Indonesia. There is 26 hotspot in 2017 close to Aek Godang, North Sumatera, Indonesia. In this study, we use a data mining approach to train and test the data of forest fire and the Fire Weather Index (FWI) from meteorological data. The aim of this study to predict the burned area and identify the forest fire in Aek Godang areas, North Sumatera. The result of this study indicated that Fire fighting and prevention activity may be one reason for the observed lack of correlation. The fact that this dataset exists indicates that there is already some effort going into fire prevention.
\end{abstract}

\section{KEYWORDS}

Forest fire; Fire Weather Index; Support Vector Machine; Machine Learning

\section{INTRODUCTION}

Forest fires are an important environmental issue, growing reasonably-priced and ecological damage whilst dangering human lives. Every year Northern Sumatra of Indonesia spends hundreds of thousands to deal with the wildfire breakout. This situation now not solely motives monetary damage however can additionally disrupt the ecological stability by way of destroying vegetation and plants and fauna [1]. Wildfire is additionally accountable for air pollution and changes in climatic circumstances over the period of time [2]. Over the decade forest fire has to turn out to be a major problem as it has endangered the lives of species. regardless of the massive charges concerned in controlling these dead fires, they are additionally an essential problem in forest fires [3]. The forests on the border of Aek Godang areas, North Sumatra had been badly affected and would be impacted through different areas in North Sumatra. The primary trouble of this study, how to computation the hotspot in this location to predict the woodland fire[4]. Firefighters are conscious of how forest fires can be unpredictable [5]. However, if this data is obtained through them as a warning about the breakout on time then this form of phenomenon can be anticipated, controlled mainly can be prevented. Many typical sciences deal with wildfire hazard analysis. In this study, based on the description above, we are aiming to remedy this 
trouble via a historical analysis of woodland and land furnace facts and the usage of weather data to predict the extent of fires that have occurred. Then we also explored information mining strategies to locate out and predict the depth of wooded area and land fires [6]. Fast detection is a key component for controlling such a phenomenon. In achieving this, alternative options are needed. one of them is the use of nearby sensor-based automatic equipment furnished by using several meteorological stations [7]. causing meteorological conditions (such as temperature and wind) to affect the wooded area and land fires, as well as knowing what a furnace index, such as the Fire Weather Index (FWI), makes use of this data. FWI is primarily based on the Index Spread Index (ISI) about the spread of furnace and wind speed, then the Buildup Index (BUI) to calculate the quantity of gasoline that reasons a fire. All of this is used as a measure for the wellknown index of heart hazards in woodland areas. In this work, we conducted statistics exploration with a data mining (DM) strategy so that we may want to predict the place of forest fires and burned land [8]. In this study, the method used is Support Vector Machines (SVM) [9] [10] and then uses four different feature selection settings (using spatial, temporal, FWI components, and weather attributes), by carrying out tests on the latest real-world data, data collected from the northern Sumatera. The satisfactory configuration end result is the use of the SVM method with 4 meteorological enter parameters (namely relative humidity, rain, temperature, and wind) and is capable to predict burnt areas from several widely wide-spread small fires. So, this know-how is very supportive and useful in enhancing preventive motion and administration of firefighting sources (equipment and people).

\section{DATA AND METHODS}

\subsection{Data}

The dataset of this study had been collect in BMKG of Aek Godang Station, North Sumatera from 2017 years[11], from the LAPAN based on the Satellite of NOAA[12] and from PKHL Direktorat Pengendalian Kebakaran Hutan[13]. There are more than 26 hotspots in 2017 close to Aek Godang, Northern Sumatera was recorded[14].

\subsection{Methods}

The forest Fire Weather Index (FWI) is a Canadian device for ranking the hazard level of wooded area and land fires which includes six aspects (Figure 1)[6]: the first is the Fine Fuel Moisture Code (FFMC) which functions to decide the numerical ranking of moisture content material of litter and other fine fuels. Then the $2 \mathrm{~d}$ is the Duff Moisture Code (DMC) which functions to discover the common moisture content of the organic layer which can indicate gasoline consumption in a medium-sized layer of grime and medium-sized wood. The $1 / 3$ is the Drought Code (DC) which functions to calculate the common quantity of water content in deep and dense natural layers. As properly as being a useful indicator of the outcomes of the dry season on forest fuels and the number of fires in deep mud layers and massive logs. The fourth is the Initial Spread Index (ISI) which features to determine the charge of fireplace spread primarily based on wind speed and FFMC and the fifth. Is the Buildup Index (BUI), useful for calculating the amount of fuel available at the time of burning. all three of these are closely related to the gasoline code. The FWI index is an indicator measuring fireplace intensity and combining the two preceding components. Although the scale used is distinctive for each issue of the FWI, the perfect cost may also indicate extra severe combustion conditions. Then the different vital element is that the gasoline humidity code requires reminiscence (time lag) of the preceding climate conditions: is 12 days for DMC, sixteen hours for FFMC, and 52 days for DC. This is an essential indicator in figuring out the depth of the wooded area and land fires that take place. 


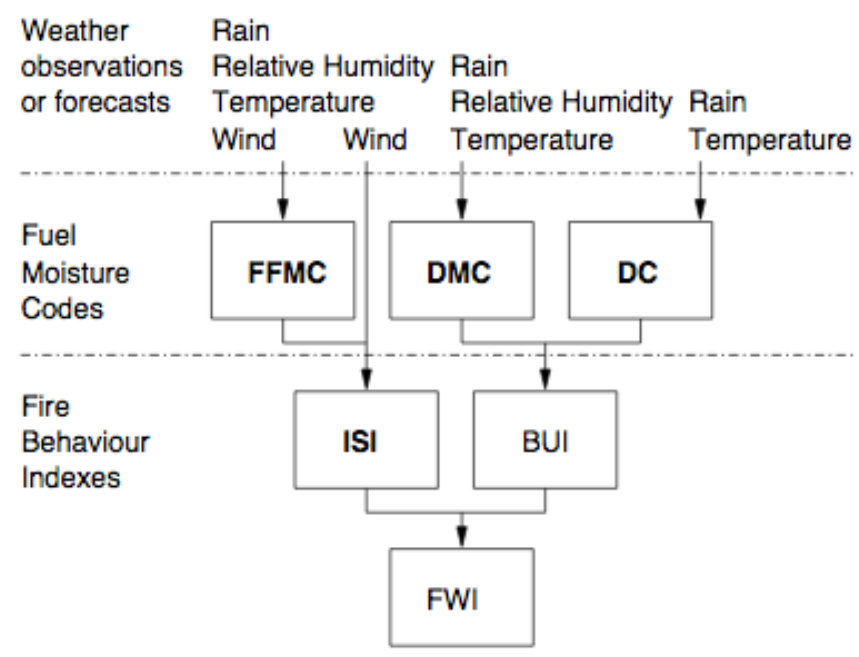

Figure 1. The Fire Weather Index structure [7]

A regression dataset $\mathrm{D}$ is made up of $k \in\{1, \ldots, N\}$ examples, each mapping an input vector $\left(x_{1}^{k}, \ldots x_{A}^{k}\right)$ to a given target $y_{\mathrm{k}}$. The error is given by: $e_{k}=y_{k}-\hat{y}_{k}$, where $\hat{y}_{\mathrm{k}}$ represents the predicted value for the $k$ input pattern. The overall performance is computed by a global metric, namely the Mean Absolute Deviation (MAD)and Root Mean Squared (RMSE)[1], which can be computed as eq.1.

$$
\begin{aligned}
M A D & =1 / N x \sum_{i=1}^{N}|y k-\hat{y} k| \\
R M S E & =\sqrt{\sum_{i=1}^{N}\left(y_{i}-\widehat{y}_{l}\right)^{2} / N}
\end{aligned}
$$

In both metrics, lower values result in better predictive models. However, the RM SE is more sensitive to high errors. Another possibility to compare regression models is the Regression Error Characteristic (REC) curve, which plots the error tolerance (x-axis), given in terms of the absolute deviation, versus the percentage point predicted by the Support Vector Machine by presenting a theoretical advantage over the Neural Network, such as the absence of a local minimum when optimizing the model. In this SVM regression, input $\mathrm{x}$ ? RA can be converted into a high-dimensional feature space, through the use of nonlinear mapping.:

$$
\hat{y}=w_{0}+\sum_{i=1}^{m} w_{i} \phi_{i}(x)
$$

Where $\boldsymbol{\phi}_{i}(x)$ represents a nonlinear transformation, according to the kernel function $\boldsymbol{K}\left(\boldsymbol{x}, \boldsymbol{x}^{\prime}\right)=$ $\sum_{i=1}^{m} \phi_{i}(x) \phi_{i}\left(x^{\prime}\right)$. To estimate the best SVM, the $\boldsymbol{\epsilon}$-insensitive loss function (Figure 4 ) is often used[1]. In presenting hyperparameters and less numerical difficulty than other kernels such as polynomials and sigmoid by using the popular Kernel Radial Basis Function

$$
K\left(x, x^{\prime}\right)=\exp \left(-\gamma\left\|x-x^{\prime}\right\|^{2}\right), \gamma>0
$$

The SVM performance is affected by three parameters: $C-a$ trade-off between the model complexity and the amount up to which deviations larger than $\boldsymbol{\epsilon}$ are to related; $\boldsymbol{\epsilon}$ - the width of the $\boldsymbol{\epsilon}$-insensitive zone; and $\gamma-$ the parameter of the kernel. Since the search space for the three 
parameters is high, the $C$ and $\boldsymbol{\epsilon}$ values will be set using theheuristics proposed in $C=3$ (for standardized inputs) and $\epsilon=3 \hat{\sigma} \sqrt{\frac{\ln (N)}{N}}$, where and $\hat{\sigma}$ is the standard deviation as predicted by a $3-$ nearest neighbor algorithm.

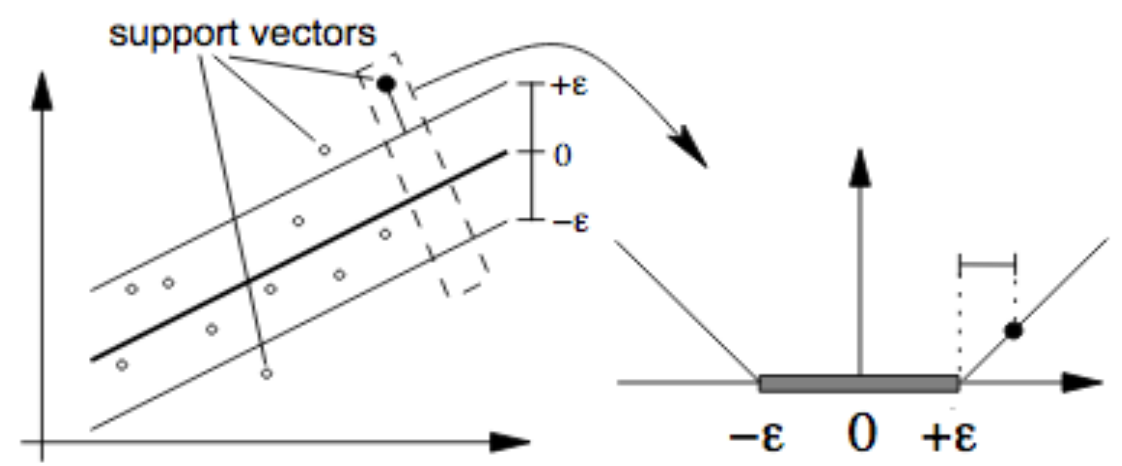

Figure 2. Example of a linear SVM regression and the $\epsilon$-insensitive loss function

\section{RESUlt AND DISCUSSIONS}

Predicting the fireplace burn of Aek Godang, the Northern Sumatera region must assist in directing resources over large areas. An exceptionally interpretable model might provide records on hearth prevention. One may consequently be inclined to seem at multi-linear regression or generalized additive models.

The result of the split the statistics into coaching and trying out sets as shown in Figure 3.

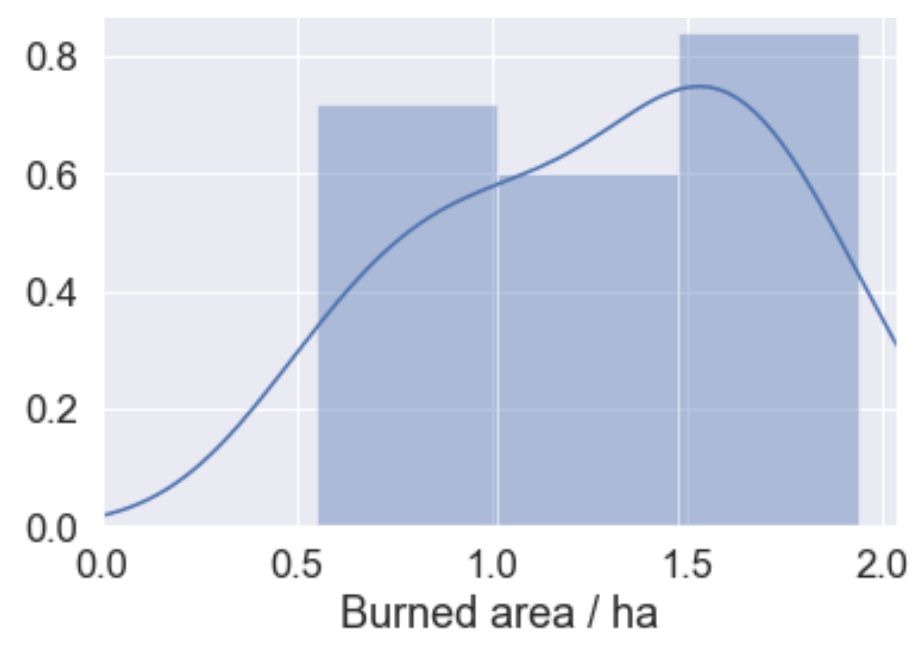

Figure 3. The distribution of the response variable

The response variable burned of Aek Godang, Northern Sumatera area, is extraordinarily skewed towards small fires. It might be beneficial to transform this with e.g. a $\log 10$ () scaling. The visual-spatial statistic result of this study is proven in Figure four Most fires manifest at central and low X-Y coordinates, excep of one very high hearth count grid reference at $(8,6)$. Comparing complete fires with the total burned region there is some proof that fires at low $\mathrm{X}$ are small and numerous, where fires at high $\mathrm{X}$ are much less accepted however larger. 


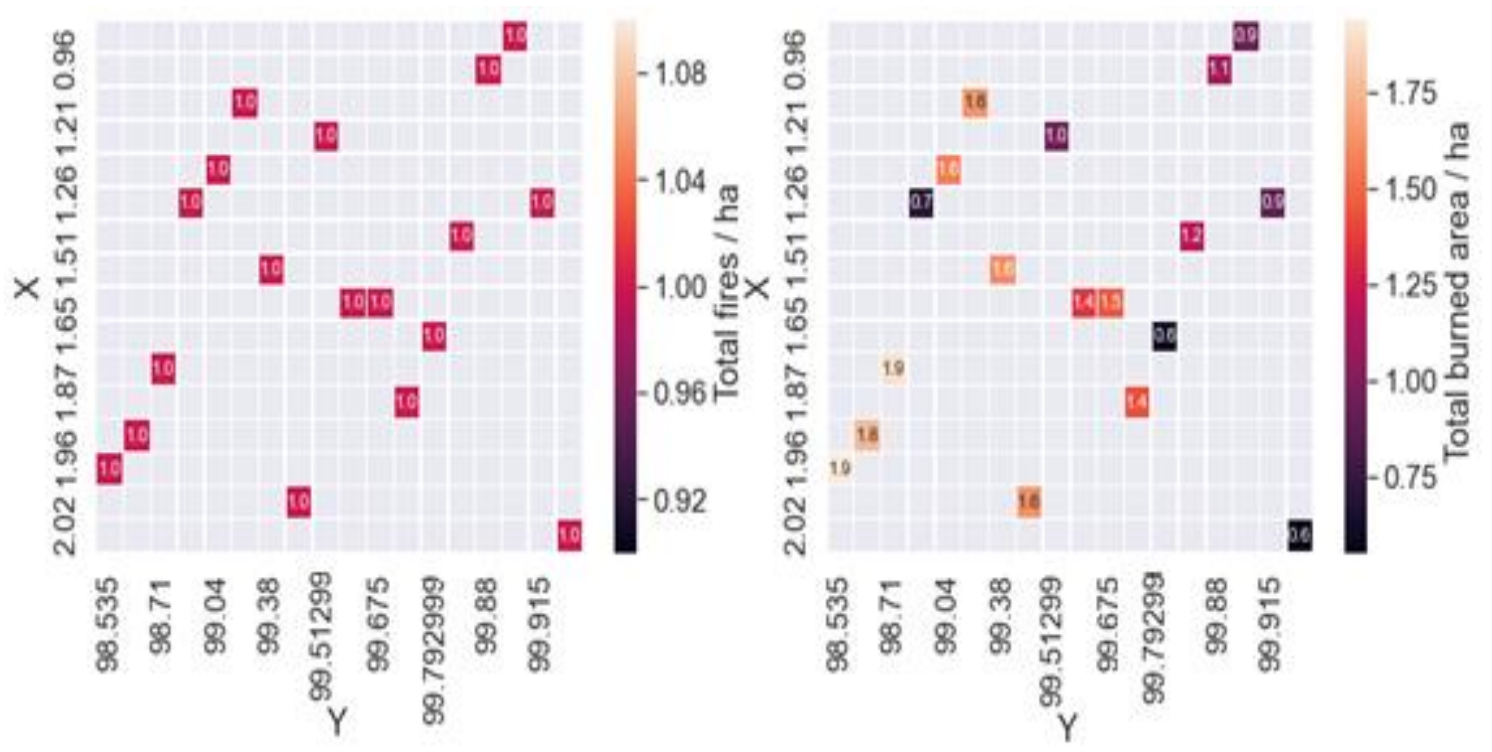

Figure 4. Visualize spatial statistics

The median burned region in Figure 5, reinforces the remaining bullet, that is to say, smaller fires dominate low- $\mathrm{X}$ regions the place large fires dominate at high- $\mathrm{X}$ regions.

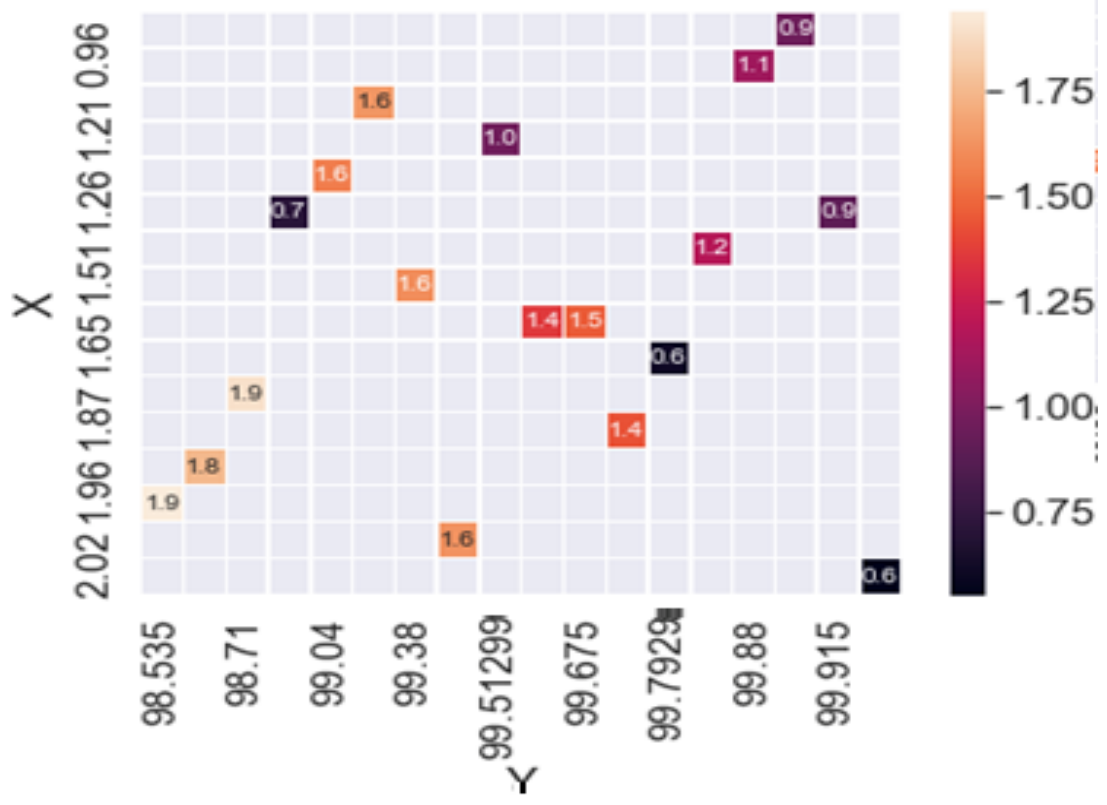

Figure 5. Median Burned

Based on the express the average burned area is biggest in March (Figure 6). However, this may also be the result of a single or a few fires in view that the width of the distribution is small. The greatest fires tend to occur in the summertime months, Aug via Sep. There is no obvious fashion in location burned on a given day of the week. 


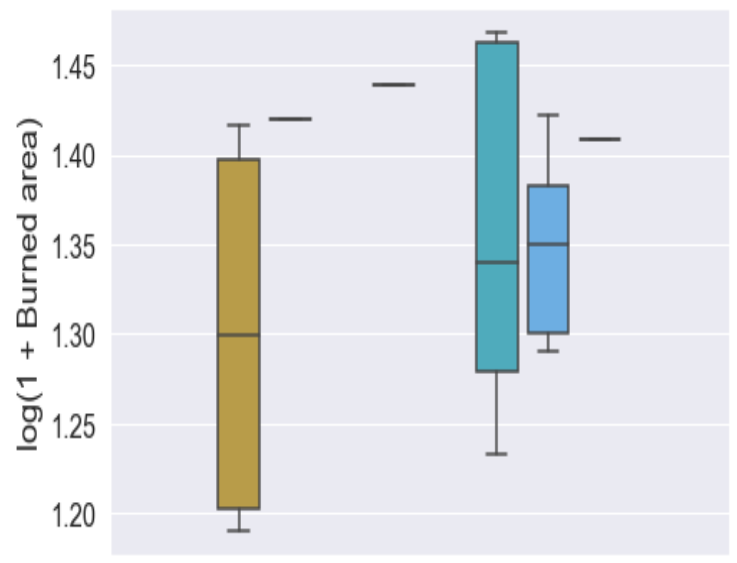

jan feb mar apr may jun jul aug sep oct nov dec month

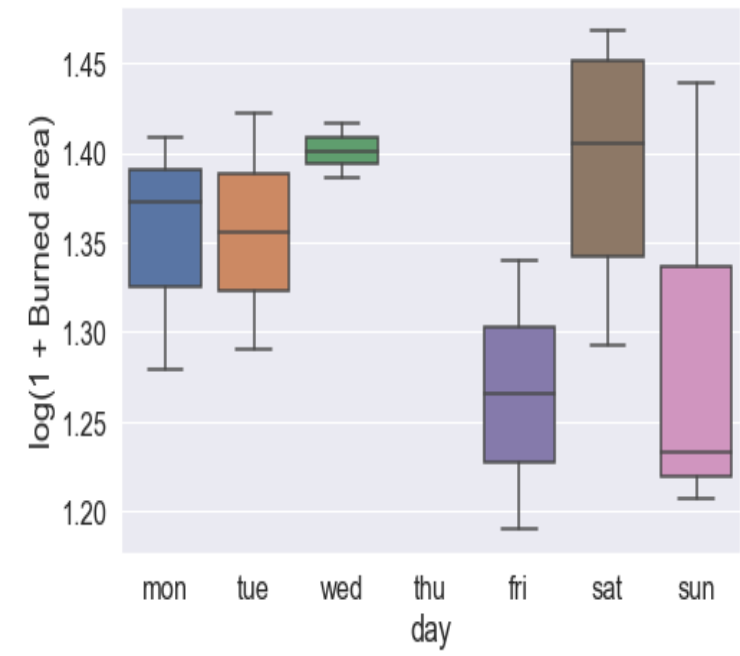

Figure 6. Categorical Variable

In Figure 7, the fire depends as a characteristic of month and day appears like most fires take place in the summertime months of August through September. Most fires manifest on the weekend, possibly pointing to human recreation.
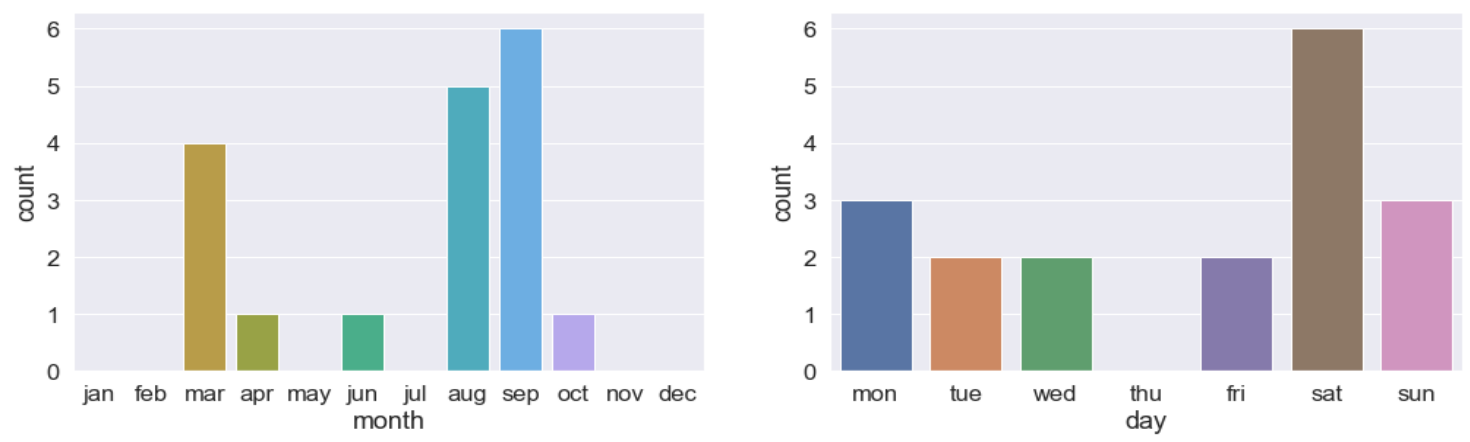

Figure 7. The fire count as a function of month and day look like

The FWI symptoms are all correlated with one another and with temperature. There may also be some (multi) collinearity, which will amplify the variance of a geared up model. It may be beneficial to mix these into a single predictor. We'll stick with the full set of predictors for now.

\begin{tabular}{|c|c|c|c|c|c|c|c|c|c|c|c|}
\hline & $x$ & $\mathbf{Y}$ & FFMC & DMC & DC & ISI & temp & RH & wind & rain & area \\
\hline$x$ & 1.000000 & -0.104349 & -0.510968 & 0.163899 & 0.173017 & -0.445531 & -0.379804 & 0.525578 & -0.320112 & 0.182948 & 0.152108 \\
\hline $\mathbf{Y}$ & -0.104349 & 1.000000 & 0.651102 & -0.698352 & -0.731524 & 0.603644 & 0.590436 & -0.580939 & 0.239158 & -0.241677 & -0.697455 \\
\hline FFMC & -0.510968 & 0.651102 & 1.000000 & -0.383860 & -0.417636 & 0.966017 & 0.906448 & -0.975714 & 0.234824 & -0.463451 & -0.367122 \\
\hline DMC & 0.163899 & -0.698352 & -0.383860 & 1.000000 & 0.995787 & -0.313409 & -0.271251 & 0.274650 & -0.212321 & 0.241341 & 0.991549 \\
\hline DC & 0.173017 & -0.731524 & -0.417636 & 0.995787 & 1.000000 & -0.339549 & -0.307984 & 0.304645 & -0.224787 & 0.251641 & 0.992462 \\
\hline ISI & -0.445531 & 0.603644 & 0.966017 & -0.313409 & -0.339549 & 1.000000 & 0.834487 & -0.978134 & 0.215194 & -0.337063 & -0.293979 \\
\hline temp & -0.379804 & 0.590436 & 0.906448 & -0.271251 & -0.307984 & 0.834487 & 1.000000 & -0.862024 & 0.186511 & -0.519856 & -0.236786 \\
\hline RH & 0.525578 & -0.580939 & -0.975714 & 0.274650 & 0.304645 & -0.978134 & -0.862024 & 1.000000 & -0.230477 & 0.425679 & 0.262224 \\
\hline wind & -0.320112 & 0.239158 & 0.234824 & -0.212321 & -0.224787 & 0.215194 & 0.186511 & -0.230477 & 1.000000 & -0.195281 & -0.215478 \\
\hline rain & 0.182948 & -0.241677 & -0.463451 & 0.241341 & 0.251641 & -0.337063 & -0.519856 & 0.425679 & -0.195281 & 1.000000 & 0.216059 \\
\hline area & 0.152108 & -0.697455 & -0.367122 & 0.991549 & 0.992462 & -0.293979 & -0.236786 & 0.262224 & -0.215478 & 0.216059 & 1.000000 \\
\hline
\end{tabular}

Figure 8. Correlation matrix 
Based on Figure 8, the cross-validated imply absolute error from bagging is 0.09 . Using default hyperparameters is not the strongest way to examine fashions in this way but we'll assume that the default hyperparameters are set to give practical starting points for most problems. This is very disappointing, the mannequin predicts a nearly regular response. There also appears to be a lower limit on the expected burned area. Does this mirror a lower restriction in the coaching data? It would be prudent to inspect this further.

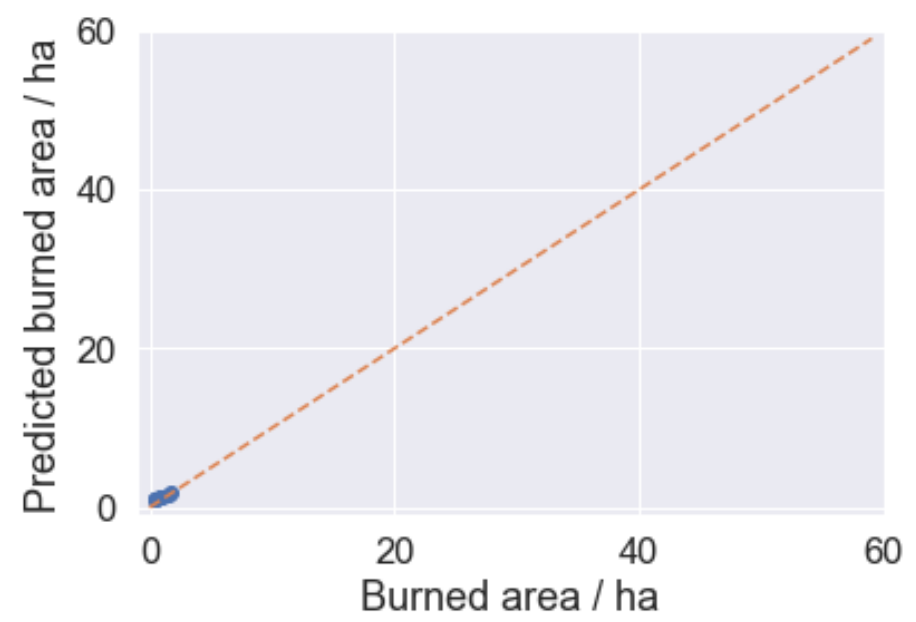

Figure 9. Test predictions against the true burned area

The test set deviance increases beyond $\sim 100$ iterations, a clear signal that the model is overfitting. It would have been useful to do this checking out on a separate validation dataset as an alternative to the check set. This would have allowed us to go back and address the overfitting. Unfortunately, this is a very difficult dataset to work within that it is small with few if any predictors nicely correlated with the response. We would likely now not get any reward for similarly reducing the measurement of the coaching set.

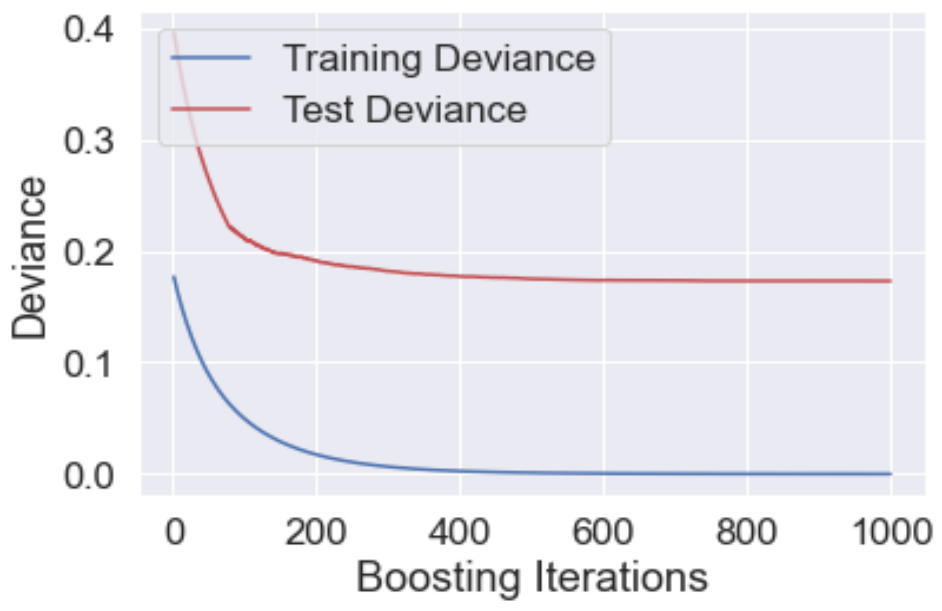

Figure 10. Training and test set deviance

All the fashions give comparable consequences and are tremendously poor, gradient boosting gives the lowest cross-validation error so we will take this forward and attempt to tune the parameters. There is no huge correlation between any one of the predictors and the response. A 
multilinear regression or generalized additive model is probably no longer going to eke out a signal. Highly nonlinear techniques might be better suited at the rate of interpretation.

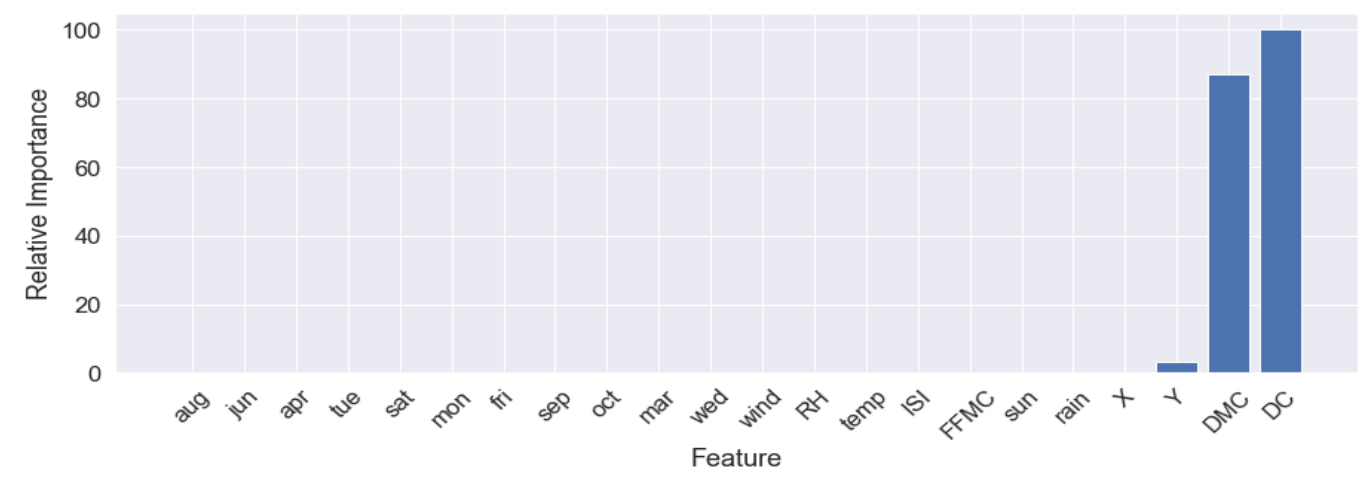

Figure 11. Feature importance

Many of the points have little or no significance in the closing model, they are probably adding noise, indicating that some feature selection might be prudent. The temperature has the easiest significance of all the features, which makes a lot of sense. However, each wind and rain have no importance. One might have expected fires to burn much less vicinity at instances of high precipitation and for high winds to fan the flames.

The wooded area fires dataset used to be presented in Cortez and Morais 2007 [1], the place the authors current an answer to this trouble the use of a trained support vector machine. In assessing the accuracy of their mannequin they produce a REC curve, which plots the error tolerance ( $\mathrm{x}$ axis), given in terms of the absolute deviation, versus the percentage of points envisioned in the tolerance (y-axis). The ideal regressor should be existing a REC region close to 0.5 .

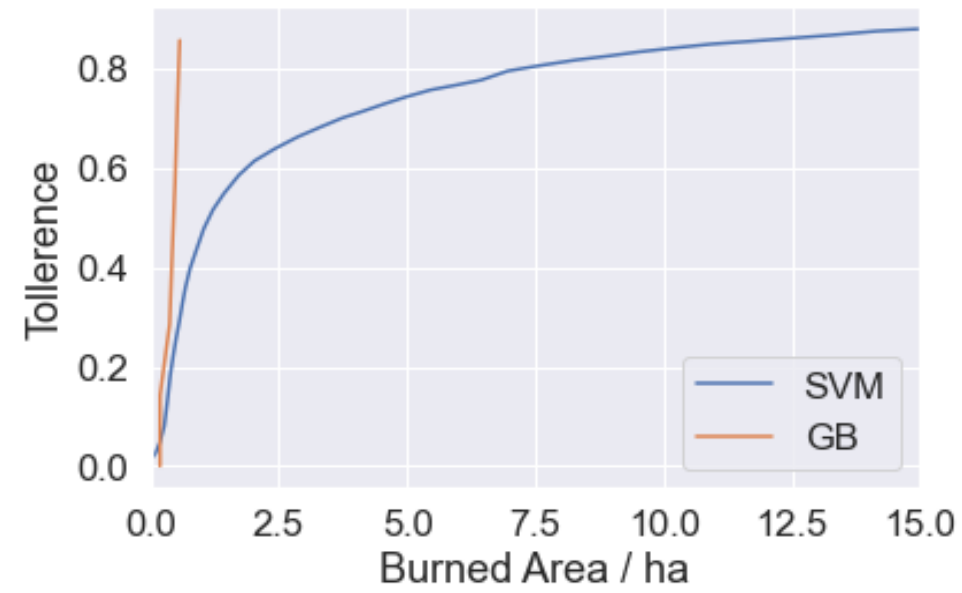

Figure 12. REC Curve

\section{Conclusions}

Based on the result, there is little correlation between the predictor variables and the response variable. It would be prudent to attempt and understand this lack of correlation better. Fire hostilities and prevention exercise may be one motive for the found lack of correlation. The truth that this dataset exists suggests that there is already some effort going into hearth prevention. One 
ought to imagine a situation in which many fires can emerge as very massive but are extinguished before they have the risk to do so. If statistics about furnace prevention are reachable it would likely be an extraordinarily precious addition to this dataset. It was once shown that the gradient boosting model used to be likely overfitting. Controlling the depth of timber and studying charge are two methods which were used to stop overfitting. Scikit-learn gives numerous more, which includes the capacity to enforce a decrease bound on the number of samples in a leaf. This limits the ability of the boosting algorithm to structure leaves that seize single outlying data points, hence decreasing variance and overfitting. As with random forests, introducing randomization into the boosting algorithm can additionally minimize variance. Scikit-learn affords two methods. First by using developing each tree with a random subsample of the education set and 2nd via randomly subsampling the points viewed for each node. In summary, a whole lot greater tuning of the mannequin is possible.

Gradient boosting based totally on the cross-validated mean absolute error from tuned gradient boosting is 0.07 , it performs characteristic selection naturally. However, with the use of a validation set, it would have been feasible to use the feature importance plot above to do some guide characteristic selection. In particular, most of the days and months have no relevance to the problem and are probably simply including noise. Unfortunately, the use of a validation set for this motive would always reduce the coaching data, in addition to contributing to the situation of attempting to eke out a susceptible sign from a small dataset.

\section{ACKNOWLEDGMENT}

We are grateful to Universitas Sumatera Utara, BMKG, LAPAN, Kementerian Lingkungan Hidup dan Kehutanan (KLHK) Rebuplik Indonesia and Universitas Methodist Indonesia.

\section{REFERENCES}

[1] P. Cortez and A. Morais, "A Data Mining Approach to Predict Forest Fires using Meteorological Data," Proc. 13th Port. Conf. Artif. Intell., no. January 2007, pp. 512-523, 2007.

[2] F. Krikken, F. Lehner, K. Haustein, I. Drobyshev, and G. J. van Oldenborgh, "Attribution of the role of climate change in the forest fires in Sweden 2018," Nat. Hazards Earth Syst. Sci., no. August, pp. $1-24,2019$.

[3] R. Singh, "Predicting Wildfire using Data Mining," no. May, 2016.

[4] M. D. Molovtsev and I. S. Sineva, "Classification Algorithms Analysis in the Forest Fire Detection Problem,” Proc. 2019 IEEE Int. Conf. \&amp;amp;amp;amp;amp;quot;Quality Manag. Transp. Inf. Secur. Inf. Technol. IT QM IS 2019, pp. 548-553, 2019.

[5] G. E. Sakr, I. H. Elhajj, G. Mitri, and U. C. Wejinya, "Artificial intelligence for forest fire prediction,” IEEE/ASME Int. Conf. Adv. Intell. Mechatronics, AIM, pp. 1311-1316, 2010.

[6] G. Wang, Y. Zhang, Y. Qu, Y. Chen, and H. Maqsood, "Early Forest Fire Region Segmentation Based on Deep Learning," Proc. 31st Chinese Control Decis. Conf. CCDC 2019, pp. 6237-6241, 2019.

[7] Nrcan, "Canadian Wildland Fire Information System | Canadian Forest Fire Weather Index (FWI) System," https://cwfis.cfs.nrcan.gc.ca/background/summary/fwi, 2020. [Online]. Available: https://cwfis.cfs.nrcan.gc.ca/background/summary/fwi. [Accessed: 19-Oct-2020].

[8] S. Ben-david, Understanding Machine Learning : From Theory to Algorithms. 2014. 
[9] N. Kerdprasop, P. Poomka, P. Chuaybamroong, and K. Kerdprasop, "Forest fire area estimation using support vector machine as an approximator," IJCCI 2018 - Proc. 10th Int. Jt. Conf. Comput. Intell., no. September, pp. 269-273, 2018.

[10] Hartono, O. S. Sitompul, Tulus, and E. B. Nababan, "Biased support vector machine and weightedSMOTE in handling class imbalance problem,” Int. J. Adv. Intell. Informatics, vol. 4, no. 1, pp. 2127, 2018.

[11] BMKG, "Badan Meteorologi, Klimatologi dan Geofisika," 2020. [Online]. Available: https://www.bmkg.go.id/cuaca/kebakaran-hutan.bmkg?index=dc\&wil=sumut\&day=obs.

[12] LAPAN, "Lembaga Penerbangan dan Antariksa Nasional," 2020. [Online]. Available: https://lapan.go.id/.

[13] D. P. K. H. PKHL, “SiPongi Karhutla Monitoring Sistem,” Jakarta, 2019.

[14] D. Bidang and P. Jauh, Informasi Titik Panas (Hotspot) Kebakaran Hutan/Lahan. 2016.

\section{AUTHORS}

Darwis Robinson Manalu, Doctoral Program Student at the Faculty of Computer Science and Information Technology, Universitas Sumatera Utara, Medan, Indonesia and Lecturer at the Faculty of Computer Science, Indonesian Methodist University email: manaludarwis@gmail.com

Muhammad Zarlis, currently a lecturer in the Computer Science Department (S3); Faculty of Computer Science and Information Technology, Universitas Sumatera Utara, Medan, Indonesia. Email: m.zarlis@yahoo.com

Herman Mawengkang, currently a lecturer in the Computer Science Department (S3); Faculty of Computer Science and Information Technology, Universitas Sumatera Utara, Medan, Indonesia. Email: hmawengkang@ yahoo.com

Opim Salim Sitompul, currently a lecturer in the Department of Computer Science (S3); Faculty of Computer Science and Information Technology, Universitas Sumatera Utara, Medan, Indonesia. email: opim@usu.ac.id
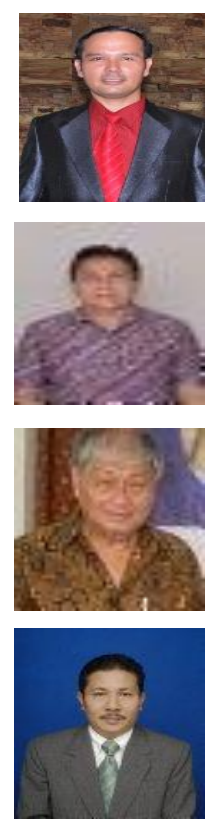

(C) 2020 By AIRCC Publishing Corporation. This article is published under the Creative Commons Attribution (CC BY) license. 